\title{
An Equilibrium Pricing Model for Weather Derivatives in a Multi-commodity Setting
}

\author{
Yongheon Lee and Shmuel S. Oren \\ Department of Industrial Engineering and Operations Research, \\ University of California, Berkeley, CA, 94720-1777 USA
}

August 20, 2008

\begin{abstract}
Many industries are exposed to weather risk. Weather derivatives can play a key role in hedging and diversifying such risk because the uncertainty in a company's profit function can be correlated to weather condition which affects diverse industry sectors differently. Unfortunately the weather derivatives market is a classical example of an incomplete market that is not amenable to standard methodologies used for derivative pricing in complete markets. In this paper, we develop an equilibrium pricing model for weather derivatives in a multi-commodity setting. The model is constructed in the context of a stylized economy where agents optimize their hedging portfolios which include weather derivatives that are issued in a fixed quantity by a financial underwriter. The supply and demand resulting from hedging activities and the supply by the underwriter are combined in an equilibrium pricing model under the assumption that all agents maximize some risk averse utility function. We analyze the gains due to the inclusion of weather derivatives in hedging portfolios and examine the components of that gain attributable to hedging and to risk sharing.
\end{abstract}

\section{Introduction}

Weather affects the revenue and net earnings in many industries. [Dutton, 2002] estimates that one third of private industry activities, representing some three trillion dollars annually, bears some degree of weather and climate risk. Energy, agriculture, leisure and insurance are good examples of weather-sensitive industries. The profit function of each industry has retail price, cost, and demand as common factors and these, possibly random, can be affected by weather. For example, the profit function of energy distribution companies, which are obligated to serve uncertain demand at a fixed regulated price, has two random components, spot price and demand. Therefore, energy companies face two types of risk, price risk in the spot market and 
volumetric risk (or quantity risk) caused by demand fluctuations. Moreover, the energy industry is exposed to weather risk because the energy demand is highly dependent on weather conditions. These price, volumetric and weather risks are all correlated; unexpected weather changes will affect energy demand and sudden demand increases result in spot price spikes. Another example of a weather-sensitive industry is agriculture where weather can affect the production while the change in supply impacts the market price. Thus a farmer is exposed both to risk of price fluctuations and to risks associated with the quantity and quality of his crop, all of which are affected by weather.

There is ample evidence in the energy industry showing that volumetric risk caused by unexpected hot or cold days leads to extremely volatile spot prices. In the summer of 1998, for example, the wholesale electricity price in the US Midwest rose to $\$ 7000 / \mathrm{MWh}$, causing the default of two East Coast electricity companies. At that time the normal price range was around $\$ 30 \sim \$ 60$. In Texas during a three-day ice storm in February 2003 electricity prices spiked to $\$ 990 /$ MWh causing a retail energy provider that was not adequately hedged to declare bankruptcy(see [Deng and Oren, 2006]). More recently on January 16, 2007 and subsequently on June 13, 2007, South Australia and Victoria experienced persistent high temperature that led to record consumption of electricity resulting in wholesale spot prices reaching $\$ 10,000 / \mathrm{MWh}$. In the natural gas market, during the first quarter of 2003 , an unusually cold winter and supply limitations drove the spot price of natural gas to a peak of $\$ 18.60 / \mathrm{MMBtu}$, as compared with a normal range of $\$ 4$ to $\$ 5 / \mathrm{MMBtu}^{1}$ Summer spikes in gas prices are also common and are largely attributable to air conditioning use on hot summer days, since $18.7 \%$ of electricity generation capacity in the US is fueled by natural gas.

In spite of strongly correlated risks, weather risk is left unhedged in most weathersensitive industries, whereas price risk has been hedged directly via commodity derivatives, if available. However, the business environment gets more competitive and rapidly changing, companies need to stabilize their revenues. This can be achieved by considering all types of risks such as price, volumetric and weather risks and managing these risks properly. One possible way to mitigate volumetric risk is through storage of the inputs and output of the corresponding production activity. Most energy commodities except electricity can be stored. However, the storability

\footnotetext{
${ }^{1}$ Gas Daily Henry Hub Price February 26, 2003.
} 
cannot fully eliminate volumetric risk because of the long lead time and cost for storage capacity expansion. An alternative approach is weather insurance. However, typical insurance contracts are intended to cover catastrophic events such as earthquakes, hurricanes, and storms. While such insurance coverage addresses the needs of most industries that are affected by disastrous events, typical weather insurance does not provide protection for revenue exposure of weather-sensitive industries that is affected by less extreme weather changes such as a warm winter and a cool summer. Hence, weather derivatives can be considered as an effective means of covering non-catastrophic weather conditions. Moreover, weather derivatives provide a simply calculated payoff based on underlying weather indices that do not require proof of loss as typical insurance contracts do. Weather derivatives are financial contracts with a certain payout that depends on weather indices like temperature, rainfall and snowfall. The most commonly used indices are Cooling-Degree-Days(CDD) and Heating-Degree-Days(HDD). In section 2 we will define CDD and HDD and give a short overview of the weather derivatives market.

Despite the advantages and increased use of weather derivatives, there is no effective pricing model for these instruments. The weather derivatives market is a classical example of an incomplete market because the underlying temperature is not a tradable commodity or equity share. Therefore, we cannot apply classical arguments based on the existence of the risk neutral probability measure or a perfect replication of the weather derivatives payoff. In a discrete time framework, [Cao and Wei, 1999] suggest an equilibrium pricing model based on the Euler equation and the fact that in equilibrium both the financial market and the goods market clear so that aggregate consumption equals the dividends generated from the risky stock. From this fact they calculate a Stochastic Discount Factor(SDF) and used it to price weather derivatives. [Brockett and Wang, 2006] derive an indifference pricing model for weather derivatives of cities which are not listed in exchanges. The concept of indifference pricing is based on the principle that the maximized utility of buyers(sellers) without weather derivatives should be equal to the maximized utility with weather derivatives accounting for the buying price(selling price) and the payoff. [Platen and West, 2004] provide a fair pricing model, based on the idea that the growth-optimal portfolio is used as a numeraire and all derivative price processes discounted by the growth optimal portfolio(benchmarked) are martingales.

In a continuous time framework, [Richards et al., 2004] suggested an equilib- 
rium pricing model based on temperature processes of a mean-reverting Brownian motion with discrete jumps and autoregressive conditional heteroscedastic errors. A standard Euler equation from the Lucas general equilibrium valuation model was applied to pricing CDD weather options. Also see [Ankirchner et al., 2006] for the indifference pricing approach in continuous time. [Hamisultane, 2007] infer the risk-neutral distribution by minimizing the second derivatives of the simulated riskneutral distribution. [Chaumont et al., 2005] discuss the market price of risk which is determined by a backward stochastic differential equation that can be translated into semi-linear partial differential equations. These later approaches can be viewed as an actuarial perspective since the price of the weather derivatives are based on the exposure of the weather derivative underwriter to weather risk. In typical weather derivative markets, however, an underwriter has only limited control over prices since the quantity of weather derivatives is fixed, unlike an insurance company that directly controls premiums with no precommitment to the number of contracts. The ultimate price of the weather derivatives is determined by supply and demand resulting from hedging activities of market agents exposed to weather risk who are optimizing their hedging portfolios. Such prices may not fully reflect the underlying stochasticity of the temperature process which would require a continuous adjustment by the underwriter of the outstanding weather derivatives quantities.

The main purpose of this paper is to derive an equilibrium pricing model for weather derivatives and to measure risk hedging and sharing gains that accrue to the market participants due to the inclusion of such instruments in their volumetric hedging portfolios. First, we will derive the optimal portfolio choices from the expected utility maximization problems of market participants. Using derived optimal demand we calculate an equilibrium price for the weather derivative by applying the market clearing condition requiring that the aggregate demand be equal to the aggregate supply. The number of the weather derivative supplied will be decided based on the issuer's single period expected utility maximization problem, however, for some industries it may make sense to take short positions which effectively increases the supply of the shorted instruments and will affect their prices. Clearly, the primary role of weather derivatives is to hedge weather risk. In a single-commodity economy, the risk hedging gain is the only gain possible. To measure the risk hedging effect we use the certain equivalent difference of maximized utility between two cases, with and without weather derivatives in a single-commodity economy. In a 
multi-commodity setting weather derivatives also provide a mechanism for risk sharing. Any two agents share risk if they employ state-contingent transfers to increase the expected utility of both by reducing their risk $^{2}$. Such risk sharing is possible due to the diversity in exposure to weather risk and different risk preferences among industries participating in weather derivatives markets. We measure the risk sharing effect in terms of certain equivalent difference of maximized utility between a single and multi-commodity economy. We note that the risk sharing effect measured by the above method includes not only the risk sharing effect but also a price effect since in the multi-commodity economy higher demand for weather derivatives due to more market participants makes the equilibrium price higher and paying more can reduce the maximized utility level of buyers. To correct such distortion we adjust the risk aversion coefficient for the issuer so as to equalize the equilibrium price in a single and multi-commodity economy.

This paper is organized as follows. In section 2 we provide an overview of the weather derivatives market and section 3 shows the mathematical formulations underlying the derivation of the equilibrium price. In section 4 we derive a closed form of the equilibrium pricing model for the special case where all the agents have the mean-variance utility functions and in section 5 we illustrate these results. Section 6 concludes and highlights the results of the paper.

\section{Overview of the Market for Weather derivatives}

Early trading of weather based instruments among energy companies started as overthe-counter(OTC) trades which means that each contract is individually negotiated. OTC trades are still used for weather derivatives for local cities which are not listed in exchanges. In September 1999 the first electronic market place for standardized weather derivatives was launched by the Chicago Mercantile Exchange(CME) with the aim of increasing liquidity, market integrity, and accessibility. This market experienced phenomenal growth and currently Cooling Degree Day (CDD) and Heating Degree Days (HDD) futures and options for 19 cities in the US, 9 cities in Europe, 6 cities in Canada, and 2 cities in Japan are being traded on the CME. These include New York, Chicago, Philadelphia, London, Paris and Berlin. Other types of contracts based on frost days and snowfall are also traded on the CME. The Weather

\footnotetext{
${ }^{2}$ Ligon (2005) The New Palgrave's Dictionary of Economics
} 
derivatives markets are expanding rapidly as diverse industries seek to manage their exposure for weather risks. The notional value of CME weather products in 2004 was $\$ 2.2$ billion, and grew ten-fold to $\$ 22$ billion through September 2005, with volume surpassing 630,000 contracts traded.[CME, 2005]. In 2006 the value of traded weather instruments rose to 45 billion.

The most commonly traded weather indices are monthly or seasonal HDD/CDD strips. The calculation of CDD/HDD is based on the average daily temperature on a day $i$, which is defined as the average of the maximum and minimum temperature during that day, i.e.,

$$
T_{i} \equiv \frac{T_{i}^{\max }+T_{i}^{\min }}{2}
$$

From here on in referring to temperature, we mean daily average temperature. Daily CDD/HDD can be defined as:

$$
\begin{aligned}
\text { daily } \mathrm{CDD}_{i} & =\max \left(T_{i}-65^{\circ} F, 0\right) \\
\text { daily } \mathrm{HDD}_{i} & =\max \left(65^{\circ} F-T_{i}, 0\right)
\end{aligned}
$$

Monthly or seasonal CDD/HDD can be defined by summing up daily CDD/HDD over the month or season. Seasonal strips bundle two or more consecutive months into a single contract. The HDD index can be interpreted as a measurement of the coldness during the contract periods relative to the industry standard $65^{\circ} \mathrm{F}$ at which people are supposed to feel comfortable. Similarly CDD is a measure of heat over the contract period relative to the $65^{\circ} \mathrm{F}$ norm.

The CME offers weather futures and options which are the same as financial futures and options except for the underlying basis. Weather options are agreements to buy or sell the value of the CDD/HDD index over the contract periods or alternatively can be interpreted as bets on the value of the CDD/HDD. Weather options give the owners the right, but not the obligation, to buy or sell at a specified strike level the specified weather index. A tradable weather derivative contract specifies six attributes: the contract type, the contract period, the underlying index, the contract city where the official temperature will be measured, the strike level, and the tick size (i.e., payoff in dollars per index unit). On the CME, for instance, the value of a degree day index, called a tick size, is $\$ 20$. The contract period should be specified as a calendar month or seasonal strip from November to March for the HDD and May to September for the CDD. 


\section{Model}

\subsection{Assumptions and Notation}

We assume that our economy is a frictionless endowment economy in a single-period planning horizon. It is implicit in the assumption of an endowment economy that the issuer of the weather derivative(underwriter) will supply a fixed number of derivatives at time 0 that will subsequently be traded in the market. Hence the price of the weather derivative is determined by the initial number of instruments issued and by the market demand. This aspect distinguishes our model from an actuarial based approach where an insurer issue as many contracts as demanded at a price determined by the issuer based on a stochastic model of temperature risk. In addition to the issuer who is typically a financial entity, our economy consists of weather-sensitive industries whose output is a commodity for which there is a liquid derivatives market (e.g., electricity, gas, wheat, etc.), We also assume that there are weather sensitive industries with no liquid derivative market for their output (e.g., tourism, ski resorts, etc.). The economy is closed in the sense that all the supply and demand for weather derivatives comes from the parties described above. We further assume that none of the market participants is involved in speculative trades of commodity derivatives other than the commodity specific to their industry, thus, all hedging activities by parties involve derivatives of the commodity they produce(or consume) if available, and weather derivatives. We assume that all market participants are expected utility maximizers. We further assume that retail prices for all commodities are stable while wholesale prices and demand quantities are volatile and correlated with weather. This is definitely true in the energy industry, which is the primary focus of this paper. In the electric power industry, for instance, electric utilities have an obligation to serve all their customers' load at fixed regulated retail prices while they procure the power in a competitive wholesale market where spot prices are highly volatile. Thus, the buyers' profit function is given by (retail price - wholesale spot price) $\times$ demand. ${ }^{3}$ From the profit function we can see that each company faces not only spot price risk but also volumetric risk. We assume that the spot price, the demand, and temperature are all correlated.

\footnotetext{
${ }^{3}$ In general, some buyers can have a 'news vendor' type profit function, characterized in terms of shortage cost, inventory cost and salvage values for the leftover stocks. But in this paper, we will not consider a 'news vendor' type profit function.
} 
In the stylized economy described above, there exist three types of financial assets; a risk free bond, a plain-vanilla weather call option with a strike $\mathrm{K}$, and commodity derivatives that include forward contracts and European call and put options for which the underlying asset is the commodity spot price. All the financial instruments mature at time 1 at which point the physical commodity is delivered and paid for. Each agent can trade financial assets at time 0 to hedge its net revenue risks so as to maximize the expected utility at maturity. In other words, each trading party is faced with the problem of maximizing the expected utility of terminal wealth subject to a budget constraint at time 0 . The issuer decides on the number of the weather call option supplied into the market so as to maximize her expected utility of terminal wealth at time 1 .

Under the multi-commodity economy, the weather derivatives create two social welfare enhancing effects, a risk hedging effect and a risk sharing effect. When considering a single-commodity case, only the hedging effect is relevant and it can be measured by the certain equivalent difference of the maximized utility with and without weather derivative. The risk sharing effect reflects possible diversification of weather risk across industries with different weather dependence (e.g. some industries may benefit from high temperature while others may be adversely affected). Such risk sharing effect can be measured by the certain equivalent difference of the maximized utility between the multi-commodity and a single-commodity economy. In section 4 we will provide a general form of an equilibrium pricing model and numerical examples illustrating the results of our analysis.

Denote a probability space triplet by $(\Omega, \mathcal{F}, \mathbb{P})$. Also let $\mathbb{Q}$ denote a risk-neutral probability measure.

○ Notation

- $\mathrm{i} \in\{0,1, \ldots, m\}$ : indices 0 to $\mathrm{m}-1$ represent buyers where $\mathrm{u}$ buyers have a liquid derivatives market and $\mathrm{v}$ buyers don't and index $\mathrm{m}$ represents the issuer of weather derivatives

- $U_{i}(\cdot)$ : The utility function of type i industry where $U_{i}: R \rightarrow \mathrm{R}$ is smooth, increasing and strictly concave on $\mathrm{R}$ and has a continuous derivative $U^{\prime}(\cdot)$ on $\mathrm{R}$

- $\Pi_{i, n}$ : The profit function of the type $\mathrm{i}$ at time $\mathrm{n}$

- $P_{i}^{R}$ : The unit retail price of type i industry

- $P_{i}$ : The unit spot price of type $i$ at terminal time

- $P_{i}^{\prime}=P_{i}^{R}-P_{i}$ : The marginal profit of selling a type i commodity 
- $D_{i}$ : The random demand for type $\mathrm{i}$ at terminal time

- $B_{n}=(1+r)^{n} B_{0}$ : The riskless bond price at time $\mathrm{n}$, where $\mathrm{r}$ is the interest rate and $B_{0}=1$

- $W_{n}$ : The weather derivative price

- $W_{i, n}^{1}$ : The weather derivative price at time $\mathrm{n}$ in a type $\mathrm{i}$ industry economy

- $I_{i}\left(D_{i}, P_{i}\right)$ : the income function of type i industry at terminal time

- $x_{i, n}\left(P_{i}\right)$ : The portfolio payoff consisting of a risk-free bond, forwards, and call and put options with various strikes in a type i industry

- $\alpha_{i, n}$ : A portfolio position of type i industry for the weather derivative at time $\mathrm{n}$

- $J\left(\Pi_{i, n}\right)$ : The maximized expected utility of type i industry at time $\mathrm{n}$

- $J_{w d}^{1}\left(\Pi_{i, n}\right)$ : The maximized expected utility of type i industry at time $\mathrm{n}$ in a singlecommodity economy with the weather derivative and commodity derivatives

- $J_{w n}^{1}\left(\Pi_{i, n}\right)$ : The maximized expected utility of type $\mathrm{i}$ industry at time $\mathrm{n}$ in a singlecommodity economy with the weather derivative and without commodity derivatives

- $J_{n d}^{1}\left(\Pi_{i, n}\right)$ : The maximized expected utility of type i industry at time $\mathrm{n}$ in a singlecommodity economy without the weather derivative and with commodity derivatives

- $J_{n n}^{1}\left(\Pi_{i, n}\right)$ : The maximized expected utility of type i industry at time $\mathrm{n}$ in a singlecommodity economy without the weather derivative and commodity derivatives

- $H E_{i, n}$ : The hedging effect for the type i industry at time $\mathrm{n}$

- $R S_{i, n}$ : The risk sharing effect for the type i industry at time $\mathrm{n}$

\subsection{Multi-Commodity Economy}

\subsubsection{Utility Maximization Problem of Buyers with a Liquid Derivatives Market}

We consider the utility maximization problem of buyers that have a liquid commodity derivatives market. For example, electricity and natural gas industry have liquid futures and options markets of which underlying asset is the spot price of electricity or natural gas. The buyer's profit function at time 1 is

$$
\Pi_{i, 1}=I_{i}\left(D_{i}, P_{i}\right)+x_{i, 1}\left(P_{i}\right)+\alpha_{i, 1} W_{1}
$$

where $x_{i, 1}\left(P_{i}\right)$ represents the optimal payoff of the commodity portfolio which is the function of the commodity price $P_{i}$. The corresponding utility maximization 
problem of buyers at time 0 is

$$
\begin{aligned}
& \max _{\left\{x_{i, 1}, \alpha_{i, 1}\right\}} E_{0}\left[U_{i}\left(\Pi_{i, 1}\right)\right] \\
& \text { s.t. } \quad E^{\mathbb{Q}}\left[\frac{x_{i, 1}\left(P_{i}\right)}{B_{1}}\right]+\alpha_{i, 1} W_{0}=0, \quad \forall i=1,2, \ldots, u
\end{aligned}
$$

where the constraint means that it costs zero to construct the portfolio with a commodity derivatives payoff $x_{i, 1}\left(P_{i}\right)$ and weather derivatives payoff $\alpha_{i, 1} W_{0}$. The expected discounted portfolio values under a risk-neutral probability measure $\mathbb{Q}$ is the price of the commodity derivatives' portfolio. Note that $x_{i, 1}\left(P_{i}\right)$ is a decision variable. For each realization $p$ of the random price $P_{i}$ we will find the optimal payoff function $x(p)$ by solving the above maximization problem (5).

[Carr and Madan, 2001] show that any twice continuously differentiable function, $f(S)$, of the terminal stock price $\mathrm{S}$ can be replicated by a unique initial position of $f\left(S_{0}\right)-f^{\prime}\left(S_{0}\right) S_{0}$ unit discount bonds, $f^{\prime}\left(S_{0}\right)$ shares, and $f^{\prime \prime}(K) d K$ out-of-themoney options of all strikes $\mathrm{K}$ :

$$
\begin{aligned}
f(S)= & {\left[f\left(S_{0}\right)-f^{\prime}\left(S_{0}\right) S_{0}\right]+f^{\prime}\left(S_{0}\right) S+\int_{0}^{S_{0}} f^{\prime \prime}(K)(K-S)^{+} d K } \\
& +\int_{S_{0}}^{\infty} f^{\prime \prime}(K)(S-K)^{+} d K
\end{aligned}
$$

Using the result (6) the optimal payoff function $x\left(P_{i}\right)$ can be rewritten as:

$$
\begin{aligned}
x\left(P_{i}\right)= & x(F) \cdot 1-x^{\prime}(F)\left(P_{i}-F\right)+\int_{0}^{F} x^{\prime \prime}(K)\left(K-P_{i}\right)^{+} d K \\
& +\int_{F}^{\infty} x^{\prime \prime}(K)\left(P_{i}-K\right)^{+} d K
\end{aligned}
$$

where $\mathrm{F}$ denotes the forward price at time 0 . Because $1,\left(P_{i}-F\right),\left(K-P_{i}\right)^{+}$, and $\left(P_{i}-K\right)^{+}$represent the payoff of the bond, forward contracts, and European put and call options respectively, the equation (7) shows that the optimal payoff $x\left(P_{i}\right)$ can be replicated by $x(F)$ units of the risk-free bonds, $x^{\prime}(F)$ units of forwards, $x^{\prime \prime}(K) d K$ units of European put options with strike $K$ for all $K<F$, and $x^{\prime \prime}(K) d K$ units of European call options with strike $K$ for all $K>F$. Since in reality there are no derivatives with continuous strikes, we need to approximate the replication by existing derivatives. [Oum et al., 2006] suggest one possible way to replicate the optimal payoff by approximating the option positions $x^{\prime \prime}(K) d K$ to the mean of two 
available strike prices. Determining the best discrete approximation to our continuous optimal portfolio is out of the scope of this paper and will not be elaborated any further.

Back to our constrained maximization problem(5), the corresponding Lagrangian function is

$$
\begin{array}{r}
L\left(x_{i, 1}\left(P_{i}\right), \alpha_{i, 1}, \lambda_{i}\right)=E_{0}\left[U_{i}\left(\Pi_{i, 1}\right)\right]-\lambda_{i}\left(E_{0}^{\mathbb{Q}}\left[\frac{x_{i, 1}\left(P_{i}\right)}{B_{1}}\right]+\alpha_{i, 1} W_{0}\right) \\
=\int_{-\infty}^{\infty} E_{0}\left[U_{i}\left(\Pi_{i, 1}\right) \mid P_{i}=p\right] f_{i}(p) d p-\lambda_{i}\left(\frac{1}{B_{1}} \int_{-\infty}^{\infty} x_{i, 1}(p) g_{i}(p) d p+\alpha_{i, 1} W_{0}\right)
\end{array}
$$

where $f_{i}(p)$ is a marginal probability density function of commodity spot price $P_{i}$ under the real probability measure $\mathbb{P}$ and $g_{i}(p)$ is a risk-neutral probability density function of $P_{i}$. If the commodity market is incomplete there may exist infinitely many risk-neutral probability measures. The ratio $\frac{g_{i}(p)}{f_{i}(p)}$ is a Radon-Nicodym derivatives for the type i commodity and satisfies $E\left[\frac{g_{i}(p)}{f_{i}(p)}\right]=1$. One of the decision variables, $x_{i, 1}\left(P_{i}\right)$, is a function of $P_{i}$ and we need the Euler equation for the functional derivatives. Taking partial derivative with respect to $x_{i, 1}\left(P_{i}\right), \alpha_{i, 1}$, and $\lambda_{i}$ gives us the first order necessary conditions as

$$
\begin{gathered}
\frac{\partial L}{\partial x_{i, 1}(p)}=E_{0}\left[U_{i}^{\prime}\left(\Pi_{i, 1}\right) \frac{\partial \Pi_{i, 1}}{\partial x_{i, 1}(p)} \mid p\right] f_{i}(p)-\lambda_{i} \frac{g_{i}(p)}{B_{1}}=0 \\
\frac{\partial L}{\partial \alpha_{i, 1}}=E_{0}\left[U_{i}^{\prime}\left(\Pi_{i, 1}\right) \frac{\partial \Pi_{i, 1}}{\partial \alpha_{i, 1}}\right]-\lambda_{i} W_{0}=0 \\
E_{0}^{\mathbb{Q}}\left[\frac{x_{i, 1}(P)}{B_{1}}\right]+\alpha_{i, 1} W_{0}=0 \quad \forall i=1,2 \ldots, u
\end{gathered}
$$

Note that the first order conditions are sufficient for optimality because the utility function is assumed to satisfy $U^{\prime}(\cdot)>0$ and $U^{\prime \prime}(\cdot)<0$. Moreover under the assumption $E_{0}\left[\left|U_{i}(\cdot)\right|\right]<\infty$ the partial derivative and the expectation operator are interchangeable. By solving the above three equations with three unknowns we can determine the optimal portfolio choices, $x_{i, 1}\left(P_{i}\right)$ and $\alpha_{i, 1}^{*}$, i.e., the structure of the optimal derivatives portfolio payoff of type i industry, and the quantity of weather derivatives that should be purchased at time 0 in order to maximize the expected utility. The optimal $\alpha_{i, 1}^{*}$ is a function of an equilibrium price $W_{0}$ and will be used as a demand function for the weather derivative. 


\subsubsection{Utility Maximization Problem of Buyers without a Liquid Deriva- tives Market}

If a type i industry does not have a liquid derivatives market, a risk-free bond and the weather derivative are the only available financial assets for hedging volumetric and price risk. Then the profit function is of the form

$$
\Pi_{j, 1}=I_{j}\left(D_{j}, P_{j}\right)+\alpha_{j, 1} W_{1}+\beta_{j, 1} B_{1}
$$

where $\beta_{j, 1}$ is the amount of money invested in a risk-free bond. The corresponding utility maximization problem of buyers at time 0 is;

$$
\begin{aligned}
& \max _{\left\{\alpha_{j, 1}, \beta_{j, 1}\right\}} E_{0}\left[U_{j}\left(\Pi_{j, 1}\right)\right] \\
& \text { s.t. } \quad \alpha_{j, 1} W_{0}+\beta_{j, 1} B_{0}=0, \quad j=1,2, \ldots, v
\end{aligned}
$$

where the constraint implies that the portfolio with $\alpha_{j, 1}$ and $\beta_{j, 1}$ has zero cost at time zero. The constraint can be rewritten as $\beta_{j, 1}=-\frac{\alpha_{j, 1} W_{0}}{B_{0}}$ and can be substituted into the profit function (12). Then we have the unconstrained maximization problem:

$$
\max _{\left\{\alpha_{j, 1}\right\}} E_{0}\left[U_{j}\left(\Pi_{j, 1}\right)\right]
$$

where $\Pi_{j, 1}=I_{j}\left(D_{j}, P_{j}\right)+\alpha_{j, 1}\left(W_{1}-W_{0} B_{1}\right)$. Since there is only one decision variable $\alpha_{j, 1}$ the optimality condition will be

$$
\frac{\partial E_{0}\left[U_{j}\left(\Pi_{j, 1}\right)\right]}{\partial \alpha_{j, 1}}=0
$$

From the above optimality condition (15) we can find the optimal quantity of weather derivatives in the case of no commodity derivatives market and the derived quantity will be regarded as the demand function for weather derivatives with an argument $W_{0}$.

\subsubsection{Utility Maximization Problem of an Issuer}

Now we consider the issuer's or underwriter's problem. The issuer is assumed to be a purely financial firm that specializes in weather derivatives and balances its budget by trading a risk-free bond, but it takes no positions in any commodity derivatives. At time 0 the underwriter will issue the weather derivatives and receive 
a price $W_{0}$. At time 1 the issuer will pay the realized payoff $W_{1}$ for the issued weather derivatives. Consequently the issuer's profit function at time 1 is

$$
\Pi_{m, 1}=\alpha_{m, 1}\left(W_{0} * B_{1}-W_{1}\right)
$$

The corresponding problem of the issuer is as follows.

$$
\max _{\left\{\alpha_{m, 1}\right\}} E_{0}\left[U_{m}\left(\Pi_{m, 1}\right)\right]
$$

The first order condition is

$$
\frac{\partial E_{0}\left[U_{m}\left(\Pi_{m, 1}\right)\right]}{\partial \alpha_{m, 1}}=0
$$

The issuer can determine the quantity of weather derivatives that will be supplied in this economy. Only this number of the weather derivatives, $\alpha_{m, 1}^{*}$, will prevail in the market.

\subsubsection{Equilibrium Price}

We next derive an equilibrium pricing formula by applying the market clearing condition. The market clearing condition means the aggregate demand should be equal to the aggregate supply and can be graphically interpreted as the intersection of the demand and supply curve. The market clearing condition is given by

$$
\sum_{i=1}^{u} \alpha_{i, 1}^{*}\left(W_{0}\right)+\sum_{j=1}^{v} \alpha_{j, 1}^{*}\left(W_{0}\right)=\alpha_{m, 1}^{*}\left(W_{0}\right)
$$

From the above equation we can derive the equilibrium price for the weather derivative. Then, the optimal choices can be expressed as real numbers and the maximized expected utility of the buyer $\mathrm{i}$ at time 1 with a liquid derivatives market, denoted by $J_{w d}\left(\Pi_{i, 1}\right)$, is

$$
J_{w d}\left(\Pi_{i, 1}\right)=E\left[U_{i}\left(I_{i}\left(D_{i}, P_{i}+x_{i, 1}^{*}\left(P_{i}\right)+\alpha_{i, 1}^{*} W_{1}\right)\right] \quad \forall i=1,2, \ldots, u\right.
$$

The certain equivalent, denoted by $C E_{w d}$, will be

$$
C E_{w d}=U_{i}^{-1}\left(J_{w d}\left(\Pi_{i, 1}\right)\right)
$$

If there is no liquid derivatives market the maximized utility and its certain equivalents are written as

$$
\begin{gathered}
J_{w n}\left(\Pi_{j, 1}\right)=E\left[U_{j}\left(I_{j}\left(D_{j}, P_{j}\right)+\alpha_{j, 1}^{*} W_{1}+\beta_{j, 1}^{*} B_{1}\right)\right] \quad \forall j=1,2, \ldots, v \\
C E_{w n}=U_{j}^{-1}\left(J_{w n}\left(\Pi_{j, 1}\right)\right)
\end{gathered}
$$




\subsection{Single-Commodity Economy}

In this section we consider a single-commodity economy because we want to evaluate the effectiveness of weather derivative in mitigating, transferring, and diversifying (via risk sharing) market risk. One possible measurement of the risk hedging and sharing effects is the certain equivalent difference of the uncertain outcomes, that are measured in dollars. To measure the hedging effect we need to examine two cases; with and without weather derivatives. Note that in this case there is no risk sharing through cross-commodity diversification. We still consider, however, two types of buyers; one with a liquid commodity derivatives market and the other without. Since they have different forms of the profit functions we need to formulate this case separately. We need to consider four cases reflecting combinations of two factors, existence of the weather derivative and the presence of a liquid derivatives market.

\subsubsection{Utility Maximization Problem of Buyers with a Liquid Derivatives Market}

In the case that there is a weather derivative in the type i commodity economy the corresponding problems of the buyer and the issuer are exactly the same as the case of the multi-commodity economy case resulting in the same optimality conditions (9) and (18) for the buyer and the issuer respectively. The only difference between a single and multi-commodity economy is the market clearing condition since a single-commodity economy has one buyer and one issuer. Instead of the aggregated demand, we use a single buyer's demand function in the market clearing condition.

$$
\alpha_{i, 1}^{*}\left(W_{i, 0}^{1}\right)=\alpha_{m, 1}^{*}\left(W_{i, 0}^{1}\right) \quad \forall i=1,2, \ldots, u
$$

This condition gives us the equilibrium price for a single-commodity economy. The maximized expected utility of the buyer with the weather derivatives in a singlecommodity economy is of the form

$$
J_{w d}^{1}\left(\Pi_{i, 1}\right)=E_{0}\left[U_{i}\left(I\left(D_{i}, P_{i}\right)+x_{i, 1}^{*}\left(P_{i}\right)+\alpha_{i, 1}^{*} W_{i, 1}^{1}\right)\right]
$$

The corresponding certain equivalent is $C E_{w d}^{1}=U_{i}^{-1}\left(J_{w d}^{1}\left(\Pi_{i, 1}\right)\right)$.

If the weather derivative is not available and only a risk-free bond and type $\mathrm{i}$ commodity derivatives are traded, the profit function of the buyers will be changed. 
The buyers will hedge risk only via the type i commodity derivatives and a risk-free bond. The issuer does not have any role in this case. The buyer's profit function is of the form

$$
\Pi_{i, 1}=I\left(D_{i}, P_{i}\right)+x_{i, 1}\left(P_{i}\right)
$$

The corresponding maximization problem is

$$
\begin{array}{ll}
\max _{\left\{x_{i, 1}\left(P_{i}\right)\right\}} & E_{0}\left[U_{i}\left(\Pi_{i, 1}\right)\right] \\
\text { s.t. } & E^{\mathbb{Q}}\left[x_{i, 1}\left(P_{i}\right)\right]=0 \quad \forall i=1,2, \ldots, u
\end{array}
$$

The above problem (27) is solved by [Oum et al., 2006] under the CARA and the mean-variance utility function. The optimality condition can be obtained by defining the Lagrangian function and taking derivatives with respect to $x_{i, 1}(P)$ and $\lambda_{i}$.

$$
\begin{gathered}
\frac{\partial L}{\partial x_{i, 1}(P)}=E_{0}\left[U_{i}^{\prime}\left(\Pi_{i, 1}\right) \frac{\partial \Pi_{i, 1}}{\partial x_{i, 1}(P)} \mid p\right] f_{i}(p)-\lambda_{i} g_{i}(p)=0 \\
E_{0}^{\mathbb{Q}}\left[x_{i, 1}(P)\right]=0 \quad i=1,2 \ldots, u
\end{gathered}
$$

After solving the above optimality conditions we can find the maximized utility and the certain equivalent as

$$
\begin{array}{r}
J_{n d}^{1}\left(\Pi_{i, 1}\right)=E_{0}\left[U_{i}\left(I_{i}\left(D_{i}, P_{i}\right)+x_{i, 1}^{*}\left(P_{i}\right)\right)\right] \\
C E_{n d}^{1}=U_{i}^{-1}\left(J_{n d}^{1}\left(\Pi_{i, 1}\right)\right)
\end{array}
$$

\subsubsection{Utility Maximization Problem without a Liquid Derivatives Mar- ket}

If weather derivative are available but there is no market for type $\mathrm{j}$ commodity derivatives, the optimality condition is the same as (15). After applying the market clearing condition with a single, not aggregated, demand and supply we can find a new equilibrium price in this single-commodity economy and the maximized utility has the form of

$$
J_{w n}^{1}\left(\Pi_{j, 1}\right)=E_{0}\left[U_{j}\left(I_{j}\left(D_{j}, P_{j}\right)+\alpha_{j, 1}^{*} W_{1}^{1}+\beta_{j, 1}^{*} B_{1}\right)\right] \quad \forall j=1,2, \ldots, v
$$

The corresponding certain equivalent is

$$
C E_{w n}=U_{j}^{-1}\left(J_{w n}^{1}\left(\Pi_{j, 1}\right)\right)
$$


If there are no weather derivative and liquid derivatives market, the buyers are exposed to all the risk. Then the buyer's profit function is $\Pi_{j, 1}=I_{j}\left(D_{j}, P_{j}\right)$ and the expected utility and the certain equivalent are written as

$$
\begin{gathered}
J_{n n}^{1}\left(\Pi_{j, 1}\right)=E_{0}\left[U_{j}\left(\Pi_{j, 1}\right)\right] \quad \forall j=1,2, \ldots, v \\
C E_{n n}^{1}=U_{j}^{-1}\left(J_{n n}^{1}\left(\Pi_{j, 1}\right)\right)
\end{gathered}
$$

\subsection{Hedging and Risk Sharing Effects}

In this section we evaluate the hedging and the risk sharing effect. As mentioned before one role of the weather derivative is to hedge the volumetric risks of the buyers. The hedging effect can be measured by subtracting the certain equivalent without the weather derivative from the certain equivalent with the weather derivative in a single-commodity economy. Thus, with a liquid derivatives market the hedging effect is given by

$$
H E_{i, 1}=C E_{w d}^{1}-C E_{n d}^{1} \quad \forall i=1, \ldots, u
$$

Without a liquid derivatives market the hedging effect is given by

$$
H E_{j, 1}=C E_{w n}^{1}-C E_{n n}^{1} \quad \forall j=1, \ldots, v
$$

The risk sharing effect exists only in the multi-commodity economy with weather derivatives. By holding weather derivatives buyers can increase their expected utilities. The difference between the certain equivalent in a single and multi-commodity economy will represent the risk sharing effect. With a liquid commodity derivatives market the risk sharing effect is

$$
R S_{i, 1}=C E_{w d}-C E_{w d}^{1} \quad \forall i=1, \ldots, u
$$

Without a liquid commodity derivatives market the risk sharing effect is

$$
R S_{j, 1}=C E_{w n}-C E_{w n}^{1} \quad \forall j=1, \ldots, v
$$

\section{Mean-Variance Utility Case}

In this section we specialize the general model described above to the case where all market participants have mean variance utility functions with possibly different risk 
aversion coefficients, i.e. $U\left(\Pi_{i}\right)=E\left[\Pi_{i}\right]-\frac{\nu_{i}}{2} \operatorname{Var}\left(\Pi_{i}\right)$ where $\nu_{i}$ denotes the risk aversion coefficient of the type i buyer. The utility value $U\left(\Pi_{i}\right)$ can be interpreted as the certain equivalent of the risky outcome $\Pi_{i}$. Under the mean-variance utility function we can, therefore, directly use utility differences to measure the risk hedging and sharing effects. Portfolio choices based on the mean-variance preference are widely accepted in financial theory to analyze decisions under risk. [Kroll et al., 1984] show that the mean-variance efficient portfolio is a good approximation of the optimized portfolio under other forms of utility functions.

\subsection{Multi-Commodity Economy}

Under the mean variance utility the Lagrangian function corresponding to problem (5) is given by

$$
\begin{aligned}
& L\left(x_{i, 1}\left(P_{i}\right), \alpha_{i, 1}\right)=\mu_{I_{i}}+\mu_{x_{i, 1}}+\alpha_{i, 1} \mu_{W_{1}}-\frac{\nu_{i}}{2}\left(\sigma_{I_{i}}^{2}+\sigma_{x_{i, 1}}^{2}+\alpha_{i, 1}^{2} \sigma_{W_{1}}^{2}\right. \\
& \left.+2\left(\sigma_{I_{i} x_{i, 1}}+\alpha_{i, 1} \sigma_{x_{i, 1} W_{1}}+\alpha_{i, 1} \sigma_{W_{1} I_{i}}\right)\right)-\lambda_{i}\left(E^{\mathbb{Q}}\left[\frac{x_{i, 1}\left(P_{i}\right)}{B_{1}}\right]+\alpha_{i, 1} W_{0}\right)
\end{aligned}
$$

If we take the point-wise partial derivative with respect to $x_{i, 1}(p)$ and the partial derivatives with respect to $\alpha_{i, 1}$ and $\lambda_{i}$ we have the following optimality conditions.

$$
\begin{gathered}
\frac{\partial L}{\partial x_{i, 1}(p)}=f_{i}(p)\left(1-\nu_{i}\left(x_{i, 1}(p)-E\left[x_{i, 1}\left(P_{i}\right)\right]+E\left[I_{i} \mid p\right]-\mu_{I_{i}}\right.\right. \\
\left.\left.+\alpha_{i, 1}\left(E\left[W_{1} \mid p\right]-\mu_{W_{1}}\right)\right)\right)-\lambda_{i} \frac{g_{i}(p)}{B_{1}} \\
\frac{\partial L}{\partial \alpha_{i, 1}}=\mu_{W_{1}}-\nu_{i}\left(\sigma_{W_{1}}^{2} \alpha_{i, 1}+\sigma_{x_{i, 1} W_{1}}+\sigma_{W_{1} I_{i}}\right)-\lambda_{i} W_{0}=0 \\
E_{0}^{\mathbb{Q}}\left[\frac{x_{i, 1}(P)}{B_{1}}\right]+\alpha_{i, 1} W_{0}=0 \quad \forall i=1,2, \ldots, u
\end{gathered}
$$

By solving the above three equations we can obtain the following result.

Proposition 1 The optimal payoff function $x_{i, 1}^{*}\left(P_{i}\right)$ of the commodity derivatives portfolio is

$$
\begin{aligned}
x_{i, 1}^{*}\left(P_{i}\right)= & \frac{1}{\nu_{i}}\left(\frac{E^{\mathbb{Q}}\left[\frac{g_{i}\left(P_{i}\right)}{f_{i}\left(P_{i}\right)}\right]-\frac{g_{i}\left(P_{i}\right)}{f_{i}\left(P_{i}\right)}}{E\left[\frac{g_{i}\left(P_{i}\right)}{f_{i}\left(P_{i}\right)}\right]}\right)-\left(E\left[I_{i} \mid P_{i}\right]-E^{\mathbb{Q}}\left[E\left[I_{i} \mid P_{i}\right]\right]\right) \\
& +E^{\mathbb{Q}}\left[x_{i, 1}^{*}\left(P_{i}\right)\right]\left(1+\frac{1}{W_{0} B_{1}}\left(E\left[W_{1} \mid P_{i}\right]-E^{\mathbb{Q}}\left[E\left[W_{1} \mid P_{i}\right]\right]\right)\right)
\end{aligned}
$$


where

$$
\begin{gathered}
E^{\mathbb{Q}}\left[X_{i, 1}^{*}\left(P_{i}\right)\right]=\frac{B_{1} W_{0}}{E\left[E\left[W_{1} \mid P_{i}\right] W_{1}\right]-\mu_{W_{1}}^{2}-\sigma_{W_{1}}^{2}} \\
\left(\frac{1}{\nu_{i}}\left(\frac{E\left[\frac{g_{i}\left(P_{i}\right)}{f_{i}\left(P_{i}\right)} W_{1}\right]}{E\left[\frac{g_{i}\left(P_{i}\right)}{f_{i}\left(P_{i}\right)}\right]}-B_{1} W_{0}\right)-\left(\mu_{I_{i}} \mu_{W_{1}}-E\left[E\left[I_{i} \mid P_{i}\right] W_{1}\right]\right)-\sigma_{W_{1} I_{i}}\right)
\end{gathered}
$$

Finally, we can find the optimal quantity of weather derivative from the optimality condition (43) as

$$
\alpha_{i, 1}^{*}=\frac{\frac{1}{\nu_{i}}\left(\frac{E\left[\frac{g_{i}\left(P_{i}\right)}{i_{i}\left(P_{i}\right)} W_{1}\right]}{E\left[\frac{g_{i}\left(P_{i}\right)}{f_{i}\left(P_{i}\right)}\right]}-B_{1} W_{0}\right)-\left(\mu_{I_{i}} \mu_{W_{1}}-E\left[E\left[I_{i} \mid P_{i}\right] W_{1}\right]\right)-\sigma_{W_{1} I_{i}}}{\mu_{W_{1}}^{2}+\sigma_{W_{1}}^{2}-E\left[E\left[W_{1} \mid P_{i}\right] W_{1}\right]}
$$

The proof is provided in the Appendix A. Note that $\alpha_{i, 1}^{*}$ is a linear function of $W_{0}$.

If there is no commodity derivatives market in the type $\mathrm{j}$ commodity we have the following optimal choice from the equation (15).

$$
\alpha_{j, 1}^{*}=\frac{\mu_{W_{1}}-B_{1} W_{0}-\nu_{j} \sigma_{I_{j} W_{1}}}{\nu_{j} \sigma_{W_{1}}^{2}} \quad \forall j=1, \ldots, v
$$

Again $\alpha_{j, 1}^{*}$ is linear in $W_{0}$.

Next the issuer's problem (17) under the mean-variance case becomes;

$$
\max _{\alpha_{m, 1}} \alpha_{m, 1}\left(B_{1} W_{0}-\mu_{W_{1}}\right)-\frac{\nu_{m}}{2} \sigma_{W_{1}}^{2} \alpha_{m, 1}^{2}
$$

From the optimality condition (18), the number of the weather derivative supplied in this economy will be

$$
\alpha_{m, 1}^{*}=\frac{B_{1} W_{0}-\mu_{W_{1}}}{\nu_{m} \sigma_{W_{1}}^{2}}
$$

Here the supply function for weather derivative is also linear in $W_{0}$. Therefore, in the mean-variance utility function, the demand and supply of the weather derivative are all linear. The intersection of the aggregate demand and the supply function will clear the weather derivative market. In other words, the equilibrium price of the weather derivative can be calculated from the following market clearing condition.

$$
\begin{aligned}
& \sum_{i=1}^{u} \frac{\frac{1}{\nu_{i}}\left(\frac{E\left[\frac{g_{i}\left(P_{i}\right)}{i_{i}\left(P_{i}\right)} W_{1}\right]}{E\left[\frac{g_{i}\left(i_{i}\right)}{f_{i}\left(P_{i}\right)}\right]}-B_{1} W_{0}\right)-\left(\mu_{I_{i}} \mu_{W_{1}}-E\left[E\left[I_{i} \mid P_{i}\right] W_{1}\right]\right)-\sigma_{W_{1} I_{i}}}{\mu_{W_{1}}^{2}+\sigma_{W_{1}}^{2}-E\left[E\left[W_{1} \mid P_{i}\right] W_{1}\right]} \\
& +\sum_{j=1}^{v} \frac{\mu_{W_{1}}-B_{1} W_{0}-\nu_{j} \sigma_{I_{j} W_{1}}}{\nu_{j} \sigma_{W_{1}}^{2}}=\frac{B_{1} W_{0}-\mu_{W_{1}}}{\nu_{m} \sigma_{W_{1}}^{2}}
\end{aligned}
$$


From the above equation, the equilibrium price of the weather derivative can be obtained if we specify a probability density function of the spot price $P_{i}$ for the commodity i under $\mathbb{P}$ and $\mathbb{Q}$ and the income structure of type i industry. As a result, the maximized utility of type i buyer is

$$
J_{w d}\left(\Pi_{i, 1}\right)=U_{i}\left(I_{i}\left(D_{i}, P_{i}\right)+x_{i, 1}^{*}\left(P_{i}\right)+\alpha_{i, 1}^{*} W_{1}\right) \quad \forall i=1, \ldots, u
$$

The maximized utility of type $\mathrm{j}$ buyer without a liquid commodity derivatives market is

$$
J_{w n}\left(\Pi_{j, 1}\right)=U_{j}\left(I_{j}\left(D_{j}, P_{j}\right)+\alpha_{j, 1}^{*} W_{1}+\beta_{j, 1}^{*} B_{1}\right) \quad \forall j=1, \ldots, v
$$

\subsection{Single-Commodity Economy}

In a single-commodity economy with weather derivatives and a liquid commodity derivatives market there is one buyer and one issuer. The revised market clearing condition under the mean-variance utility is

$$
\begin{aligned}
& \frac{\frac{1}{\nu_{i}}\left(\frac{E\left[\frac{g_{i}\left(P_{i}\right)}{f_{i}\left(P_{i}\right)} W_{1}\right]}{E\left[\frac{g_{i}\left(P_{i}\right)}{f_{i}\left(P_{i}\right)}\right]}-B_{1} W_{0}\right)-\left(\mu_{I_{i}} \mu_{W_{1}}-E\left[E\left[I_{i} \mid P_{i}\right] W_{1}\right]\right)-\sigma_{W_{1} I_{i}}}{\mu_{W_{1}}^{2}+\sigma_{W_{1}}^{2}-E\left[E\left[W_{1} \mid P_{i}\right] W_{1}\right]} \\
& =\frac{B_{1} W_{0}-\mu_{W_{1}}}{\nu_{m} \sigma_{W_{1}}^{2}}
\end{aligned}
$$

The maximized utility in this case will be

$$
J_{w d}^{1}\left(\Pi_{i, 1}\right)=U_{i}\left(I\left(D_{i}, P_{i}\right)+x_{i, 1}^{*}\left(P_{i}\right)+\alpha_{i, 1}^{*} W_{1}\right) \quad \forall i=1,2, \ldots, u
$$

If there is a weather derivative but no commodity derivatives market, the market clearing condition is

$$
\frac{\mu_{W_{1}}-B_{1} W_{0}-\nu_{j} \sigma_{I_{j} W_{1}}}{\nu_{j} \sigma_{W_{1}}^{2}}=\frac{B_{1} W_{0}-\mu_{W_{1}}}{\nu_{m} \sigma_{W_{1}}^{2}}
$$

And the maximized utility is given by

$$
J_{w n}^{1}\left(\Pi_{j, 1}\right)=U_{j}\left(I\left(D_{j}, P_{j}\right)+\alpha_{j, 1}^{*} W_{1}+\beta_{j, 1}^{*} B_{1}\right) \quad \forall j=1,2, \ldots, v
$$

In a single-commodity economy without weather derivatives and with a liquid derivatives market the optimal solution to the type i buyers is provided in the following proposition. 
Proposition 2 The optimal payoff function $x_{i, 1}^{*}(p)$ in case of no weather derivative has the form of

$$
x_{i, 1}^{*}(p)=\frac{1}{\nu_{i}}\left(E^{\mathbb{Q}}\left[\frac{g_{i}(p)}{f_{i}(p)}\right]-\frac{g_{i}(p)}{f_{i}(p)}\right)+E^{\mathbb{Q}}\left[E\left[I_{i, 1} \mid p\right]\right]-E\left[I_{i, 1} \mid p\right]
$$

The proof of Proposition 2 is provided in the Appendix B. Then the buyer's maximized utility is given by

$$
J_{n d}^{1}\left(\Pi_{i, 1}\right)=U_{i}\left(I_{i}\left(D_{i}, P_{i}\right)+x_{i, 1}^{*}\left(P_{i}\right)\right) \quad \forall i=1,2, \ldots, u
$$

If there are no weather derivative and liquid commodity derivatives market the buyer's maximized utility is the form of

$$
J_{n n}^{1}\left(\Pi_{j, 1}\right)=U_{j}\left(I_{j}\left(D_{j}, P_{j}\right)\right) \quad \forall j=1,2, \ldots, v
$$

Now we can measure the hedging effect (36) and (37) and the risk sharing effect (38) and (39) under the mean-variance preference. In next section, we calculate these effects numerically for specific data.

\section{$5 \quad$ Numerical Examples}

In this section we illustrate the equilibrium pricing model and the risk hedging and sharing effects with a numerical examples based on the mean variance utility function. We apply our pricing model to a plain-vanilla weather call option with a strike of $85^{\circ} \mathrm{F}$, which may be in the portfolio during a hot summer day. However, this example can be extended to CDD/HDD indexed call or put options if we specify the probability density functions of CDD/HDD indices during the contract period. We assume that there are 5 market participants, an issuer and the four types of the buyers. Each buyer's commodity demand and spot price are positively or negatively correlated with temperature and they may have a liquid derivatives market. For convenience we label the four buyers as buyer 1 trough buyer 4 . Buyer 1, which may be an electricity distribution company, faces positive correlation among demand, spot price, and temperature and it can trade commodity derivatives in the liquid derivatives market. Demand faced by buyer 2 is negatively correlated with temperature and there are tradable commodity derivatives. Buyer 3 faces a positive correlation between demand and temperature but does not have a commodity derivatives market. Buyer 4 faces a negative correlation between demand and temperature and has 
no derivatives market to trade in. All the buyer types have the same form of the income function which reflects selling at a fixed retail price and buying in a volatile wholesale price (a typical situation for energy utilities in restructured electricity or gas markets), i.e. $I_{i}\left(D_{i}, P_{i}\right)=\left(P_{i}^{R}-P_{i}\right) D_{i}$. We also assume that $\mathbb{P}=\mathbb{Q}$ in each commodity market. This assumption has been justified in the Nordic electricity market by [Audet et al., 2004]. Under this assumption, we can simplify the optimal quantities for the weather derivative defined by the optimality condition (46) as

$$
\alpha_{i, 1}^{*}=\frac{\frac{1}{\nu_{i}}\left(\mu_{W 1}-B_{1} W_{0}\right)-\left(\mu_{I_{i}} \mu_{W_{1}}-E\left[E\left[I_{i} \mid P_{i}\right] W_{1}\right]\right)-\sigma_{W_{1} I_{i}}}{\mu_{W_{1}}^{2}+\sigma_{W_{1}}^{2}-E\left[E\left[W_{1} \mid P_{i}\right] W_{1}\right]}
$$

Our previous result (44) for the optimal portfolio payoff of type i commodity can be simplified as

$$
x_{i, 1}^{*}\left(P_{i}\right)=\mu_{I_{i}}-E\left[I_{i} \mid P_{i}\right]-\alpha_{i, 1} W_{0} B_{1}\left(1+\frac{1}{W_{0} B_{1}}\left(E\left[W_{1} \mid P_{i}\right]-\mu_{W 1}\right)\right)
$$

If commodity derivatives are not available, the optimal choices of a weather call option is the same as (47) since we use a risk-neutral probability measure $\mathbb{Q}$ in a commodity derivatives market. Then the market clearing condition can be written as

$$
\begin{array}{r}
\sum_{i=1}^{2} \frac{\frac{1}{\nu_{i}}\left(\mu_{W_{1}}-B_{1} W_{0}\right)-\left(\mu_{I_{i}} \mu_{W_{1}}-E\left[E\left[I_{i} \mid P_{i}\right] W_{1}\right]\right)-\sigma_{W_{1} I_{i}}}{\mu_{W_{1}}^{2}+\sigma_{W_{1}}^{2}-E\left[E\left[W_{1} \mid P_{i}\right] W_{1}\right]} \\
+\sum_{j=1}^{2} \frac{\mu_{W_{1}}-B_{1} W_{0}-\nu_{j} \sigma_{I_{j} W_{1}}}{\nu_{j} \sigma_{W_{1}}^{2}}=\frac{B_{1} W_{0}-\mu_{W_{1}}}{\nu_{m} \sigma_{W_{1}}^{2}}
\end{array}
$$

which results in the equilibrium price as

$$
W_{0}=\frac{\sum_{i=1}^{2} \frac{\Delta_{i}}{\Gamma_{i}}+\sum_{j=1}^{2} \frac{\Lambda_{j}}{\nu_{j} \sigma_{W_{1}}^{2}}+\frac{\mu_{W_{1}}}{\nu_{m} \sigma_{W_{1}}^{2}}}{B_{1}\left(\frac{1}{\nu_{m} \sigma_{W_{1}}^{2}}+\sum_{i=1}^{2} \frac{1}{\nu_{i} \Gamma_{i}}+\sum_{j=1}^{2} \frac{1}{\nu_{j} \sigma_{W_{1}}^{2}}\right)}
$$

where $\Delta_{i}=\frac{1}{\nu_{i}} \mu_{W_{1}}-\left(\mu_{I_{i}} \mu_{W_{1}}-E\left[E\left[I_{i} \mid P_{i}\right] W_{1}\right]\right)-\sigma_{W_{1} I_{i}}, \Gamma_{i}=\mu_{W_{1}}^{2}+\sigma_{W_{1}}^{2}-E\left[E\left[W_{1} \mid P_{i}\right] W_{1}\right]$ and $\Lambda_{j}=\mu_{W_{1}}-\nu_{j} \sigma_{I_{j} W_{1}}$.

We assumed that temperature $\mathrm{T}$ follows a normal distribution with mean $\mu_{T}$ and variance $\sigma_{T}^{2}$. Demand $D_{i}$ and the spot price $P_{i}$ of the type i commodity are assumed to be log-normally distributed and correlated with temperature T. To price the weather call option, we use a Monte-Carlo simulation which enables us to numerically calculate the various expectation, conditional expectation, and covariances. 


\begin{tabular}{cccc}
\hline & $\mathrm{T}$ & $D_{i}$ & $P_{i}$ \\
\hline \hline $\mathrm{T}$ & $\sigma_{T}^{2}$ & $a_{1} \sigma_{T} e^{0.5\left(a_{i}^{2}+b_{i}^{2}\right)+c_{i}}$ & $d_{i} \sigma_{T} e^{0.5\left(d_{i}^{2}+e_{i}^{2}+f_{i}^{2}\right)+g_{i}}$ \\
$D_{i}$ & $\cdot$ & $e^{2 c_{i}+a_{i}^{2}+b_{i}^{2}}\left(e^{a_{i}^{2}+b_{i}^{2}}-1\right)$ & $e^{c_{i}+g_{i}+0.5\left(a_{i}^{2}+b_{i}^{2}+d_{i}^{2}+e_{i}^{2}+f_{i}^{2}\right)}\left(e^{a_{i} d_{i}+b_{i} e_{i}}-1\right)$ \\
$P_{i}$ & $\cdot$ & $\cdot$ & $e^{2 g_{i}+d_{i}^{2}+e_{i}^{2}+f_{i}^{2}}\left(e^{d_{i}^{2}+e_{i}^{2}+f_{i}^{2}}-1\right)$ \\
\hline
\end{tabular}

Table 1: Covariance Matrix

We define temperature, demand, and the spot price as

$$
\begin{gathered}
T=\mu_{T}+\sigma_{T} Z \\
D_{i}=e^{a_{i} Z+b_{i} Z_{i, 1}+c_{i}} \\
P_{i}=e^{d_{i} Z+e_{i} Z_{i, 1}+f_{i} Z_{i, 2}+g_{i}} \quad \forall i=1,2,3,4
\end{gathered}
$$

where $a_{i}, b_{i}, c_{i}, d_{i}, e_{i}, f_{i}$, and $g_{i}$ are constant and $Z, Z_{i, 1}$, and $Z_{i, 2}$ are independent standard normal random variables. We then have the mean vector of demand and the spot price as

$$
\left(\mu_{D_{i}}, \mu_{P_{i}}\right)=\left(e^{c_{i}+0.5\left(a_{i}^{2}+b_{i}^{2}\right)}, e^{g_{i}+0.5\left(d_{i}^{2}+e_{i}^{2}+f_{i}^{2}\right)}\right)
$$

and the covariance matrix $\Sigma$ as shown in Table 1 . Because we have 7 parameters and 7 equations from the mean vector and the covariance matrix for each i, we can determine the parameters $a_{i}, b_{i}, \ldots, g_{i}$ so that random variables $\mathrm{T}, D_{i}$, and $P_{i}$ have the specified correlations. Note that our equilibrium pricing formula (61) includes the conditional expectations, $E\left[I_{i} \mid P_{i}\right]$ and $E\left[W_{i} \mid P_{i}\right]$. The distribution of the random variable $E\left[I_{i} \mid P_{i}\right]$ can be found from

$$
\begin{array}{r}
E\left[I_{i} \mid P_{i}=p\right]=\left(P_{i}^{R}-p\right) E\left[D_{i} \mid P_{i}=p\right] \\
\ln D_{i} \mid P_{i} \sim N\left(c_{i}+\rho_{i} \sqrt{\frac{a_{i}^{2}+b_{i}^{2}}{d_{i}^{2}+e_{i}^{2}+f^{2}}}\left(\ln P_{i}-g_{i}\right),\left(a_{i}^{2}+b_{i}^{2}\right)\left(1-\rho_{i}^{2}\right)\right)
\end{array}
$$

where $\rho_{i}=\frac{a_{i} d_{i}+b_{i} e_{i}}{\sqrt{\left(a_{i}^{2}+b_{i}^{2}\right)\left(d_{i}^{2}+e_{i}^{2}+f_{i}^{2}\right)}}$. In addition in order to get $E\left[W_{i} \mid P_{i}\right]$ we need to find the distribution of the random variable $T \mid P_{i}$ and then we can estimate $E\left[W_{i} \mid P_{i}\right]$ by Monte-Carlo simulation. The distribution of $T \mid P_{i}$ is known as

$$
T \mid P_{i} \sim N\left(\mu_{T}+\frac{\sigma_{T} d_{i}\left(\ln P_{i}-g_{i}\right)}{d_{i}^{2}+e_{i}^{2}+f_{i}^{2}}, \frac{\sigma_{T}^{2}\left(e_{i}^{2}+f_{i}^{2}\right)}{d_{i}^{2}+e_{i}^{2}+f_{i}^{2}}\right)
$$

In this example, we vary the correlation coefficient corresponding to buyer 1 , denoted by $\rho$ with temperature. All other parameters are fixed. In addition temperature T 
(a) Buyer 1

\begin{tabular}{cccc}
\hline & $\mathrm{T}$ & $D_{1}$ & $P_{1}$ \\
\hline \hline $\mathrm{T}$ & 1 & vary & 0.3 \\
$D_{1}$ & vary & 1 & 0.5 \\
$P_{1}$ & 0.3 & 0.5 & 1 \\
\hline
\end{tabular}

(c) Buyer 3

\begin{tabular}{cccc}
\hline & $\mathrm{T}$ & $D_{2}$ & $P_{2}$ \\
\hline \hline $\mathrm{T}$ & 1 & 0.7 & 0.3 \\
$D_{3}$ & 0.7 & 1 & 0.3 \\
$P_{3}$ & 0.3 & 0.3 & 1 \\
\hline
\end{tabular}

(b) Buyer 2

\begin{tabular}{cccc}
\hline & $\mathrm{T}$ & $D_{2}$ & $P_{2}$ \\
\hline \hline $\mathrm{T}$ & 1 & -0.6 & -0.2 \\
$D_{2}$ & -0.6 & 1 & 0.4 \\
$P_{2}$ & -0.2 & 0.4 & 1 \\
\hline
\end{tabular}

(d) Buyer 4

\begin{tabular}{cccc}
\hline & $\mathrm{T}$ & $D_{2}$ & $P_{2}$ \\
\hline \hline $\mathrm{T}$ & 1 & -0.6 & -0.2 \\
$D_{4}$ & -0.6 & 1 & 0.3 \\
$P_{4}$ & -0.2 & 0.3 & 1 \\
\hline
\end{tabular}

Table 2: Correlation Coefficient of the Buyers

is assumed to be $\mathrm{N}(80,25)$. The risk aversion coefficients of all buyers are equal to 0.1 . The issuer's risk aversion coefficient is assumed to be 0.01 . Table 2 shows the correlation coefficient corresponding to the four buyers among temperature, demand, and spot price. Other market parameters for buyer 1 which represents an electricity distribution company are estimated from Energy Information Administration web sites. ${ }^{4}$ Demand and spot price are $9.474 \times 10^{6} \mathrm{MWh}$ and $\$ 99.47 / \mathrm{MWh}$. Finally, the variances of demand and spot price of the buyer 1 are 3 and 2 respectively. All other variances of the buyer 2,3 , and 4 are assumed to be 2 .

Figure 1 shows the equilibrium price and the optimal quantities of weather call options of the four buyers. In Figure 1(a) the actuarial price is defined as the discounted expected value of the weather call option under the real world probability measure $\mathbb{P}$. Figure 1(b) shows that the buyer 1 and 4 short and the buyer 2 and 3 long the weather call option.

As we expect from equation (62) Figure 2 shows the linear aggregated demand and supply curves under the mean-variance utility function with correlation 0.8.

The risk hedging and the risk sharing effects corresponding to each buyer are shown in Figure 3. Figure 3 demonstrates that how much the buyers can increase their maximum utility by employing the weather call option. The risk hedging and sharing effects for buyer 1 and 2 are relatively small but more significant for buyers 3 and 4. This result is due to the existence of commodity derivatives. Because buyers 1 and 2 can construct portfolios consisting of commodity derivatives with continuous

\footnotetext{
${ }^{4}$ www.eia.doe.gov
} 


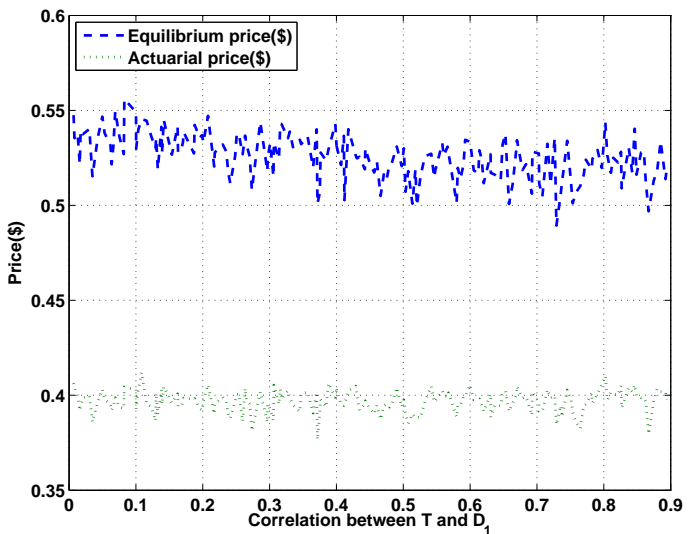

(a) Equilibrium Price

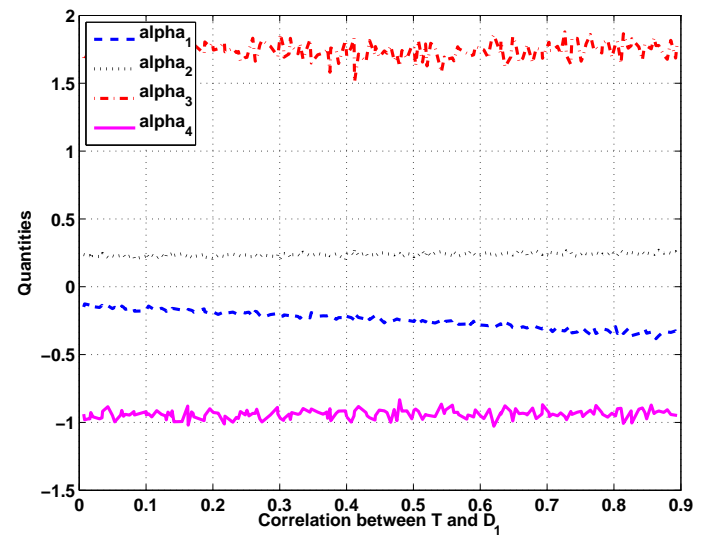

(b) Optimal Choices

Figure 1: Equilibrium Price and Choices

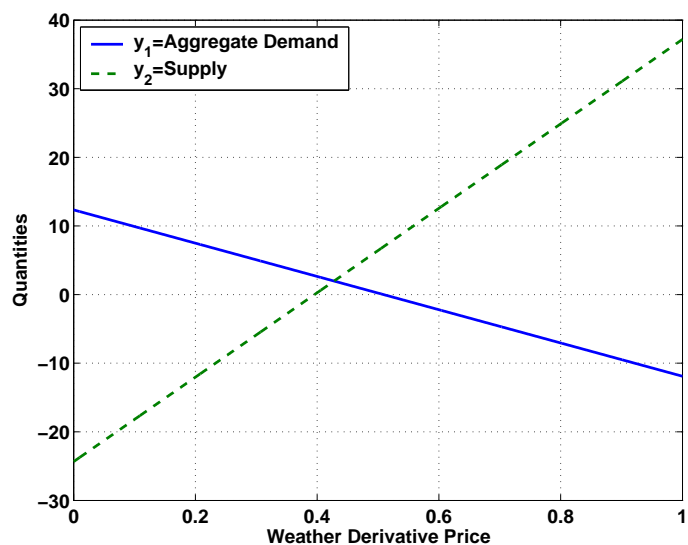

Figure 2: Supply and Demand Curve 


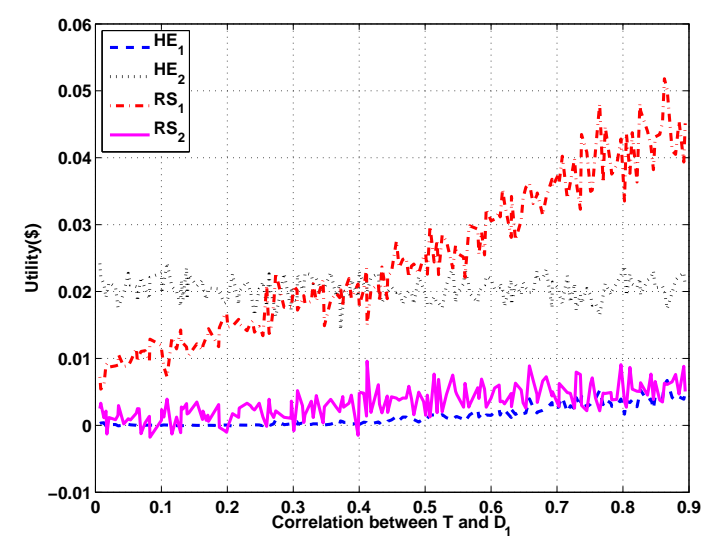

(a) Buyer 1 and 2

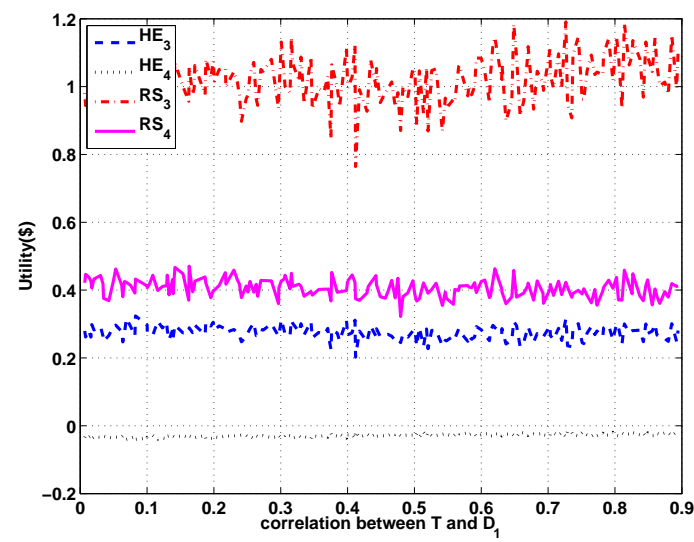

(b) Buyer 3 and 4

Figure 3: Hedging and Risk Sharing Effects

strike prices and the weather call options are only one part of their hedging portfolios, the effect of the weather call option for buyers 1 and 2 is much smaller than the corresponding effect for buyers 3 and 4 that must rely only on weather call option in order to hedge risk. Importantly, if the strike prices of commodity options are discrete with only few number of the strike prices, which is more realistic, the risk hedging and sharing effects attributable to weather derivatives are expected to be higher.

The utility improvement shown by Figure 3 is caused by reducing the variance of demand and spot price via the weather call option and other commodity derivatives(if available) and sharing the volumetric risk with other market participants. This risk(or variance) reduction can be shown by the probability density functions(p.d.f.) of the profit function $\Pi_{i}$ before and after hedging risk. Figure 4 illustrates the p.d.f. of the buyers 1 and 2's profit functions for three cases ; exposure to all risk, after hedging with commodity derivatives only, and after hedging with commodity derivatives and the weather call option. The p.d.f. before hedging is widely spread, which means that the buyer is exposed to high net revenue risk but after including commodity derivatives the risk is greatly reduced. However, the p.d.f. of the profit function after including commodity derivatives and the weather call option is very similar to the p.d.f. of the profit function with commodity derivatives only.

Figure 5 shows the p.d.f. of the profit function for buyers 3 and 4 before and 


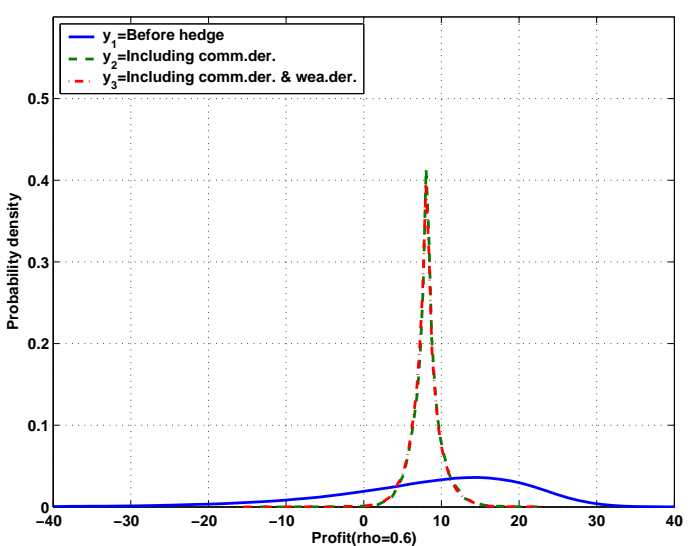

(a) Buyer 1

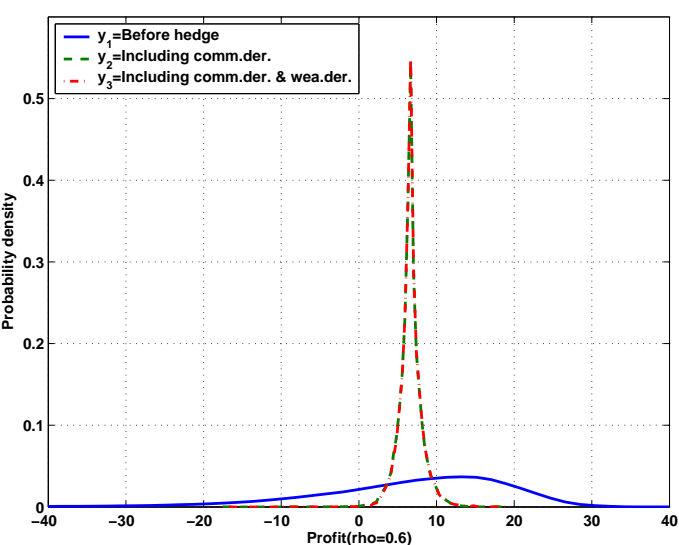

(b) Buyer 2

Figure 4: P.D.F. of Buyer 1 and 2's Profit Function $\left(\rho_{1}=0.6\right)$

after hedging. By employing the weather call option buyers 3 and 4 can reduce the variance of the profit function, which improve their mean-variance utility value.

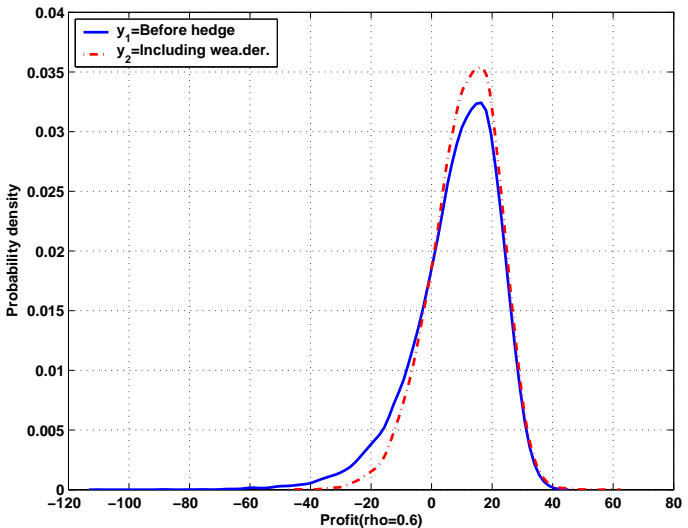

(a) Buyer 3

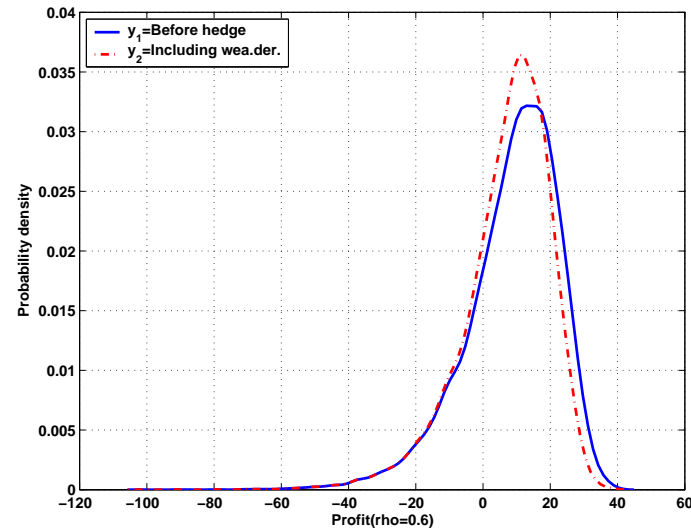

(b) Buyer 4

Figure 5: P.D.F. of the Buyer 3 and 4's Profit Function $\left(\rho_{1}=0.6\right)$

Table 3 shows the variance of the profit function when the buyer 1's correlation to temperature is 0.6 .

Finally, Figure 6 illustrates the optimal payoff of the portfolio with commodity derivatives for buyers 1 and 2 when the correlation $\rho$ between temperature $\mathrm{T}$ and demand $D_{1}$ is 0.3 and 0.6. Because we change the correlation $\rho$ and not the correlation between temperature and spot price the resulting graphs look very similar. 


\begin{tabular}{ccccc}
\hline & Buyer 1 & Buyer 2 & Buyer 3 & Buyer 4 \\
\hline Before Hedging & 170.0013 & 164.4937 & 192.6060 & 197.4552 \\
Including Comm.Der. & 3.9816 & 2.5077 & & \\
Including Wea.Der. & & & 126.3753 & 175.2812 \\
Including Comm.Der. and Wea. Der. & 3.9410 & 2.4158 & & \\
\hline
\end{tabular}

Table 3: Variance of the Profit Function

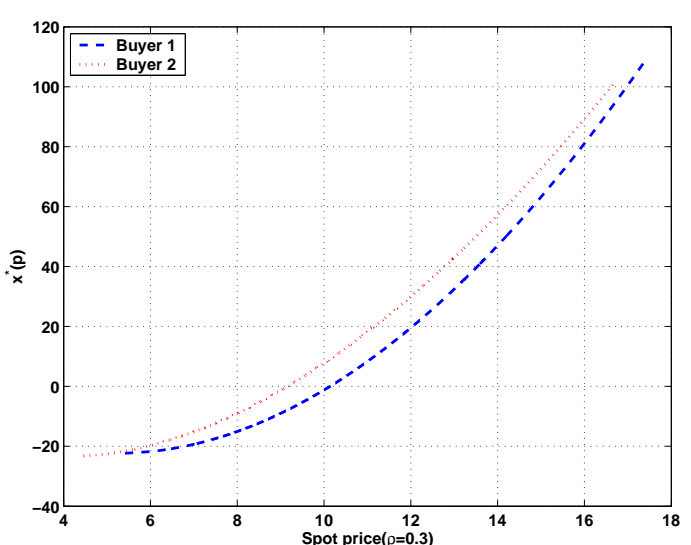

(a) Optimal $x^{*}(P)(\rho=0.3)$

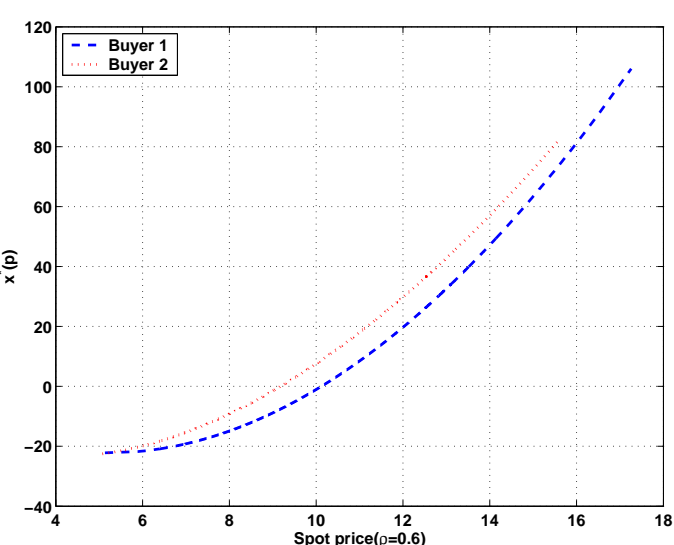

(b) Optimal $x^{*}(P)(\rho=0.6)$

Figure 6: Optimal Payoff $x^{*}(P)$ of the Commodity Derivatives Portfolio

\section{Conclusion}

Many industries are directly or indirectly exposed to weather risk. Although catastrophic events such as storms and hurricanes cause serious damage to most industries, even less extreme weather conditions can significantly affect the revenue of weather-sensitive industries. Weather derivatives provide an effective way to mitigate financial losses due to weather. However, there is no standard pricing model because of the market incompleteness.

In this paper we propose an equilibrium pricing model in a multi-commodity setting that is driven by demand for weather derivatives which is derived from hedging and risk diversification activities in weather sensitive industries. As part of our analysis we measure the risk hedging and sharing effects of the weather derivative both of which contribute to increasing the expected utility of risk averse agents that include these instruments in their hedging portfolios. To price the weather 
derivative we assume that there are buyers and an issuer in a closed and frictionless endowment economy and all of them are utility maximizers. By solving the utility maximization problems of the market participants we determine the optimal demand and supply functions for weather derivatives and obtain their equilibrium prices by invoking a market clearing condition. In the multi-commodity economy the weather derivative has two effects; the risk hedging effect and the risk sharing effect while in a single-commodity economy there is only a risk hedging effect since there is no counter-party to share risk. We measure these effects in terms of certain equivalent differences among various cases.

Under the mean-variance utility function we were able to derive closed form expression for equilibrium prices and the measurement of the risk hedging and sharing effects. Such expression will be useful in future empirical work that will attempt to calibrate the model parameter to market data. Numerical examples employing Monte-Carlo simulations show the equilibrium price and optimal choices for all available assets under various correlations between temperature and demand. In addition the numerical examples verify that weather derivative improves hedging and risk diversification capability, especially in situations where commodity derivatives are not available.

\section{References}

[Ankirchner et al., 2006] Ankirchner, S., Imkeller, P., and Popier, A. (2006). Optimal cross hedging of insurance derivatives. Working paper.

[Audet et al., 2004] Audet, N., Heiskanen, P., Keppo, J., and Vehvilainen, I. (2004). Modeling electricity forward curve dynamics in the nordic market. Modelling Prices in Competitive Electricity Markets, D.W. Bunn (ed.), Wiley Series in Financial Economics, pages 251-265.

[Brockett and Wang, 2006] Brockett, P. L. and Wang, M. (2006). Portfolio effects and valuation of weather derivatives. The Financial Review, 41.

[Cao and Wei, 1999] Cao, M. and Wei, J. (1999). Pricing weather derivative: an equilibrium approach. Working paper.

[Carr and Madan, 2001] Carr, P. and Madan, D. (2001). Optimal positioning in derivative securities. Quantitative Finance, 1:19-37. 
[Chaumont et al., 2005] Chaumont, S., Imkeller, P., Muller, M., and Horst, U. (2005). A simple model for trading climate risk. Quarterly Journal of Economic Research, 74.

[CME, 2005] CME (2005). An introduction to cme weather products. www.cme.com/weather.

[Deng and Oren, 2006] Deng, S. and Oren, S. S. (2006). Electricity derivatives and risk management. Energy, 31.

[Dutton, 2002] Dutton, J. A. (2002). Opportunities and priorities in a new era for weather and climate services. American Meteorological Society.

[Hamisultane, 2007] Hamisultane, H. (2007). Extracting information from the market to price the weather derivatives. Icfai Journal of Derivatives Markets, 4:17-46.

[Kroll et al., 1984] Kroll, Y., Levy, H., and Markowitz, H. M. (1984). Mean-variance versus direct uility maximization. The Journal of Finance, 39, No.1:47-61.

[Oum et al., 2006] Oum, Y., Oren, S. S., and Deng, S. (2006). Hedging quantity risks with standard power options in a competitive wholesale electricity market. Naval Research Logistics, 53.

[Platen and West, 2004] Platen, E. and West, J. (2004). A fair pricing approach to weather derivatives. Asia-Pacific Financial Markets, 11:23-53.

[Richards et al., 2004] Richards, T. J., Manfredo, M. R., and Sanders, D. R. (2004). Pricing weather derivatives. American Journal of Agricultural Economics, 86. 


\section{APPENDIX}

\section{A Proof of Proposition 4.1: the optimal $x_{i, 1}\left(P_{i}\right)$ and $\alpha_{i}$}

We know that

$$
\begin{aligned}
\frac{\partial E\left[x_{i, 1}\right]}{\partial x_{i, 1}(p)} & =\frac{\partial\left(\int_{-\infty}^{\infty} x_{i, 1}(p) f_{i}(p) d p\right)}{\partial x_{i, 1}(p)}=f_{i}(p) \\
\frac{\partial \sigma_{x_{i, 1}}^{2}}{\partial x_{i, 1}(p)} & =\frac{\partial\left(\int_{-\infty}^{\infty} x_{i, 1}(p)^{2} f_{i}(p) d p-\left(\int_{-\infty}^{\infty} x_{i, 1}(p) f_{i}(p) d p\right)^{2}\right)}{\partial x_{i, 1}(p)} \\
& =2 f_{i}(p)\left(x_{i, 1}(p)-\int_{-\infty}^{\infty} x_{i, 1}(p) f_{i}(p) d p\right) \\
\sigma_{I_{i} x_{i, 1}} & =E\left[I_{i} x_{i, 1}\right]-E\left[I_{i}\right] E\left[x_{i, 1}\right] \\
\text { where } E\left[I_{i} x_{i, 1}\right] & =\int_{-\infty}^{\infty} E\left[I_{i} x_{i, 1}(p) \mid P=p\right] f_{i}(p) d p \\
& =\int_{-\infty}^{\infty} x_{i, 1}(p) E\left[I_{i} \mid P_{i}=p\right] f_{i}(p) d p \\
\sigma_{x_{i, 1} W_{1}} & =E\left[x_{i, 1} W_{1}\right]-E\left[x_{i, 1}\right] E\left[W_{1}\right] \\
E\left[x_{i, 1} W_{1}\right] & =\int_{-\infty}^{\infty} E\left[x_{i, 1}(p) W_{1} \mid P_{i}=p\right] f_{i}(p) d p \\
& =\int_{-\infty}^{\infty} x_{i, 1}(p) E\left[W_{1} \mid P_{i}=p\right] f_{i}(p) d p
\end{aligned}
$$

Combining the above results and the Lagrangian function (40), we can find the following optimality conditions by taking partial derivatives.

$$
\begin{gathered}
\frac{\partial L}{\partial x_{i, 1}^{*}(p)}=f_{i}(p)\left(1-\nu_{i}\left(x_{i, 1}^{*}(p)-E\left[x_{i, 1}^{*}\left(P_{i}\right)\right]+E\left[I_{i} \mid p\right]-\mu_{I_{i}}\right.\right. \\
\left.\left.+\alpha_{i}^{*}\left(E\left[W_{1} \mid p\right]-\mu_{W 1}\right)\right)\right)-\lambda_{i}^{*} \frac{g_{i}(p)}{B_{1}}=0 \\
\frac{\partial L}{\partial \alpha_{i}^{*}}=\mu_{W_{1}}-\nu_{i}\left(\sigma_{W_{1}}^{2} \alpha_{i}^{*}+E\left[x_{i, 1}^{*}\left(P_{i}\right) W_{1}\right]\right. \\
\left.-E\left[x_{i, 1}^{*}\left(P_{i}\right)\right] E\left[W_{1}\right]+\sigma_{W_{1} I_{i}}\right)-\lambda_{i}^{*} W_{0}=0 \\
E_{0}^{\mathbb{Q}}\left[\frac{x_{i, 1}(P)}{B_{1}}\right]+\alpha_{i, 1}^{*} W_{0}=0 \quad i=0,1 \ldots, m-1
\end{gathered}
$$

If we substitute $\lambda_{i}$ of (75) into (74) and rearrange it we obtain

$$
x_{i, 1}^{*}(p)=\frac{1}{\nu_{i}}\left(1-\frac{g_{i}(p)}{f_{i}(p) W_{0} B_{1}}\left(\mu_{W_{1}}-\nu_{i}\left(\sigma_{W_{1}}^{2} \alpha_{i}^{*}+E\left[x_{i, 1}^{*}\left(P_{i}\right) W_{1}\right]\right.\right.\right.
$$




$$
\begin{aligned}
& \left.\left.\left.-E\left[x_{i, 1}^{*}\left(P_{i}\right)\right] E\left[W_{1}\right]+\sigma_{W_{1} I_{i}}\right)\right)\right) \\
& +E\left[X_{i, 1}^{*}\left(P_{i}\right)\right]-E\left[I_{i} \mid p\right]+\mu_{I_{i}}-\alpha_{i}\left(E\left[W_{1} \mid p\right]-\mu_{W_{1}}\right)
\end{aligned}
$$

The above equation implies that

$$
\begin{aligned}
x_{i, 1}^{*}\left(P_{i}\right)= & \frac{1}{\nu_{i}}\left(1-\frac{g_{i}\left(P_{i}\right)}{f_{i}\left(P_{i}\right) W_{0} B_{1}}\left(\mu_{W_{1}}-\nu_{i}\left(\sigma_{W_{1}}^{2} \alpha_{i}+E\left[x_{i, 1}^{*}\left(P_{i}\right) W_{1}\right]\right.\right.\right. \\
& \left.\left.\left.-E\left[x_{i, 1}^{*}\left(P_{i}\right)\right] E\left[W_{1}\right]+\sigma_{W_{1} I_{i}}\right)\right)\right) \\
& +E\left[X_{i, 1}^{*}\left(P_{i}\right)\right]-E\left[I_{i} \mid P_{i}\right]+\mu_{I_{i}}-\alpha_{i}\left(E\left[W_{1} \mid P_{i}\right]-\mu_{W_{1}}\right)
\end{aligned}
$$

Taking the expectation of (78) under $\mathbb{P}$ and rearranging, we have

$$
E\left[x_{i}^{*}\left(P_{i}\right) W_{1}\right]=\frac{1}{\nu_{i}}\left(\mu_{W_{1}}-\frac{W_{0} B_{1}}{E\left[\frac{g_{i}(P)}{f_{i}(P)}\right]}\right)-\alpha_{i} \sigma_{W_{1}}^{2}+E\left[X_{i, 1}^{*}\left(P_{i}\right)\right] E\left[W_{1}\right]-\sigma_{W_{1} I_{i}}
$$

Plugging (79) into (78) and rearranging give us

$$
\begin{aligned}
x_{i, 1}^{*}\left(P_{i}\right)= & \frac{1}{\nu_{i}}\left(1-\frac{\frac{g_{i}\left(P_{i}\right)}{f_{i}\left(P_{i}\right)}}{E\left[\frac{g_{i}\left(P_{i}\right)}{f_{i}\left(P_{i}\right)}\right]}\right)+E\left[x_{i, 1}^{*}\left(P_{i}\right)\right]-E\left[I_{i} \mid P_{i}\right]+\mu_{I_{i}} \\
& -\alpha_{i}\left(E\left[W_{1} \mid P_{i}\right]-\mu_{W_{1}}\right)
\end{aligned}
$$

If we take the expectation under $\mathbb{Q}$ on both sides of (80) we have

$$
\begin{aligned}
E^{\mathbb{Q}}\left[x_{i, 1}^{*}\left(P_{i}\right)\right]= & \frac{1}{\nu_{i}}\left(1-\frac{E^{\mathbb{Q}}\left[\frac{g_{i}\left(P_{i}\right)}{f_{i}\left(P_{i}\right)}\right]}{E\left[\frac{g_{i}\left(P_{i}\right)}{f_{i}\left(P_{i}\right)}\right]}\right)+E\left[x_{i, 1}^{*}\left(P_{i}\right)\right]-E^{\mathbb{Q}}\left[E\left[I_{i} \mid P_{i}\right]\right] \\
& +\mu_{I_{i}}-\alpha_{i}\left(E^{\mathbb{Q}}\left[E\left[W_{1} \mid P_{i}\right]\right]-\mu_{W_{1}}\right)
\end{aligned}
$$

Subtracting (81) from (80) to cancel out $E\left[x_{i, 1}^{*}\left(P_{i}\right)\right]$, plugging $\alpha_{i}^{*}$ of equation(76), and rearranging give us the following.

$$
\begin{aligned}
x_{i, 1}^{*}\left(P_{i}\right)= & \frac{1}{\nu_{i}}\left(\frac{E^{\mathbb{Q}}\left[\frac{g_{i}\left(P_{i}\right)}{f_{i}\left(P_{i}\right)}\right]-\frac{g_{i}\left(P_{i}\right)}{f_{i}\left(P_{i}\right)}}{E\left[\frac{g_{i}\left(P_{i}\right)}{f_{i}\left(P_{i}\right)}\right]}\right)-\left(E\left[I_{i} \mid P_{i}\right]-E^{\mathbb{Q}}\left[E\left[I_{i} \mid P_{i}\right]\right]\right) \\
& +E^{\mathbb{Q}}\left[x_{i, 1}^{*}\left(P_{i}\right)\right]\left(1+\frac{1}{W_{0} B_{1}}\left(E\left[W_{1} \mid P_{i}\right]-E^{\mathbb{Q}}\left[E\left[W_{1} \mid P_{i}\right]\right]\right)\right)
\end{aligned}
$$

Now $x_{i}^{*}\left(P_{i}\right)$ is the function of $E^{Q}\left[x_{i}^{*}(P)\right]$. From equation (75) we will try to find closed form of $E^{Q}\left[x_{i}^{*}(P)\right]$. If we integrate the optimality condition (74) on both sides, we have $\lambda_{i}=B_{1}$. As we multiply $W_{1}$ on both sides of the equation (82) and 
take the expectation under $\mathbb{P}$, we have

$$
\begin{array}{r}
E\left[x_{i, 1}^{*}\left(P_{i}\right) W_{1}\right]=\frac{1}{\nu_{i} E\left[\frac{g_{i}\left(P_{i}\right)}{f_{i}\left(P_{i}\right)}\right]}\left(E^{\mathbb{Q}}\left[\frac{g_{i}\left(P_{i}\right)}{f_{i}\left(P_{i}\right)}\right] \mu_{W_{1}}-E\left[\frac{g_{i}\left(P_{i}\right)}{f_{i}\left(P_{i}\right)} W_{1}\right]\right) \\
-\left(E\left[E\left[I_{i} \mid P_{i}\right] W_{1}\right]-\mu_{W_{1}} E^{\mathbb{Q}}\left[E\left[I_{i} \mid P_{i}\right]\right]\right) \\
+E^{\mathbb{Q}}\left[x_{i, 1}^{*}\left(P_{i}\right)\right]\left(\mu_{W_{1}}+\frac{1}{B_{1} W_{0}}\left(E\left[E\left[W_{1} \mid P_{i}\right] W_{1}\right]-\mu_{W_{1}} E^{\mathbb{Q}}\left[E\left[W_{1} \mid P_{i}\right]\right]\right)\right)
\end{array}
$$

Moreover, $E\left[x_{i, 1}^{*}\left(P_{i}\right)\right]$ can be found by taking expectation of the equation (82) and it is the function of $E^{Q}\left[x_{i}^{*}(P)\right]$. If we substitute $\lambda_{i}=B_{1}$, equation(83), and $E\left[x_{i, 1}^{*}\left(P_{i}\right)\right]$ into (75) and simplify we can find $E^{Q}\left[x_{i}^{*}(P)\right]$ as follows.

$$
\begin{array}{r}
E^{\mathbb{Q}}\left[x_{i, 1}^{*}\left(P_{i}\right)\right]=\frac{B_{1} W_{0}}{E\left[E\left[W_{1} \mid P_{i}\right] W_{1}\right]-\mu_{W_{1}}^{2}-\sigma_{W_{1}}^{2}} \\
\times\left(\frac{1}{\nu_{i}}\left(\frac{E\left[\frac{g_{i}\left(P_{i}\right)}{f_{i}\left(P_{i}\right)} W_{1}\right]}{E\left[\frac{g_{i}\left(P_{i}\right)}{f_{i}\left(P_{i}\right)}\right]}-B_{1} W_{0}\right)-\left(\mu_{I_{i}} \mu_{W_{1}}-E\left[E\left[I_{i} \mid P_{i}\right] W_{1}\right]\right)-\sigma_{W_{1} I_{i}}\right)
\end{array}
$$

Note $E\left[\frac{g_{i}\left(P_{i}\right)}{f_{i}\left(P_{i}\right)}\right]=1$ since the ratio is a Radon-Nicodym derivative for the commodity i market. Now we can find $x_{i}^{*}(P)$ by plugging (84) into $(82)$ and $\alpha_{i}^{*}=-\frac{E^{Q}\left[x_{i}^{*}(P)\right]}{B_{1} W_{0}}$. Q.E.D.

\section{B Proof of Proposition 2: the optimal $x_{i, 1}\left(P_{i}\right)$ in case of no weather derivative}

The Lagrangian function for the buyers hedging problem is of the form

$$
L\left(x_{i, 1}\left(P_{i}\right)\right)=\mu_{I_{i}}+\mu_{x_{i, 1}}-\frac{\nu_{i}}{2}\left(\sigma_{I_{i}}^{2}+\sigma_{x_{i, 1}}^{2}+2 \sigma_{I_{i} x_{i, 1}}\right)-\lambda_{i} E^{\mathbb{Q}}\left[x_{i, 1}\left(P_{i}\right)\right]
$$

The first order conditions are

$$
\begin{gathered}
\frac{\partial L}{\partial x_{i, 1}(p)}=f_{i}(p)\left(1-\nu_{i}\left(x_{i, 1}(p)-E\left[x_{i, 1}\left(P_{i}\right)\right]+E\left[I_{i} \mid p\right]-\mu_{I_{i}}\right)\right)-\lambda_{i} g_{i}(p)=0 \\
E_{0}^{\mathbb{Q}}\left[x_{i, 1}(P)\right]=0 \quad i=1,2, \ldots, u
\end{gathered}
$$

Integrating both sides of (86) provides $\lambda_{i}=1$ and rearranging (86) gives us

$$
x_{i, 1}(p)=\frac{1}{\nu_{i}}\left(1-\frac{g_{i}(p)}{f_{i}(p)}\right)+E\left[x_{i, 1}\left(P_{i}\right)\right]-E\left[I_{i, 1} \mid p\right]+\mu_{I_{i}}
$$

Taking the expectation under $\mathbb{Q}$ we have

$$
E^{\mathbb{Q}}\left[x_{i, 1}\left(P_{i}\right)\right]=\frac{1}{\nu_{i}}\left(1-E^{\mathbb{Q}}\left[\frac{g_{i}\left(P_{i}\right)}{f_{i}\left(P_{i}\right)}\right]\right)+E\left[x_{i, 1}\left(P_{i}\right)\right]-E^{\mathbb{Q}}\left[E\left[I_{i, 1} \mid P_{i}\right]\right]+\mu_{I_{i}}=0
$$


After rearranging the equation (89) we have

$$
E\left[x_{i, 1}\left(P_{i}\right)\right]=E^{\mathbb{Q}}\left[E\left[I_{i, 1} \mid p\right]\right]-\mu_{I_{i}}-\frac{1}{\nu_{i}}\left(1-E^{\mathbb{Q}}\left[\frac{g_{i}(p)}{f_{i}(p)}\right]\right)
$$

If we plug (90) into (88) we obtain the optimal $x_{i, 1}^{*}\left(P_{i}\right)$ given in (57). Q.E.D.

Acknowledgement: This research was supported by a grant from the Coleman Fung Risk Management Research Center at the University of California at Berkeley, by the Center for Electric Reliability Technology Solutions (CERTS) on behalf of the Department of Energy, by NSF Grants EEC 0119301 and by the Power Systems Engineering Research Center. 